\title{
Coupling between beam-type vibration and oval-type vibration of a cylindrical water storage tank
}

\author{
A. Maekawa \& K. Fujita \\ Institute of Nuclear Safety System, Inc. Japan
}

\begin{abstract}
This paper describes the vibration tests, in which sinusoidal wave excitations with large input are conducted to the scale model tank of a thin-walled cylindrical water storage tank, and the theoretical analysis on the vibratory behaviours which are observed during the vibration tests. Large input excitation tests are carried out, in which the test tank is excited intensively by sinusoidal waves of a resonance frequency. The response of the tank, which means beamtype vibration, is not excited in proportion to the input acceleration above a certain level. Since oval-type vibrations largely appear on the sidewall of the tank in the tests, the interaction of oval-type vibrations over beam-type vibrations is considered. Concerning the deformation of the sidewall of tank by the oval-type vibrations, it is found that a large decrease in the flexural rigidity reduces the response of beam-type vibrations. A nonlinear vibration model is proposed assuming the flexural rigidity depends on the amplitude of oval-type vibrations. The analysis using this model has a good agreement with the results of the tests. Thus, it is demonstrated both empirically and analytically that the response of beam-type vibrations is reduced and the resonance frequency of beam-type vibrations is lowered by the coupling with oval-type vibrations.

Keywords: coupling, oval-type vibration, beam-type vibration, cylindrical water storage tank, response reduction, nonlinear vibration model.
\end{abstract}

\section{Introduction}

A cylindrical water/fluid storage tank, widely used in various fields including power stations and chemical plants, must be designed to ensure a high level of seismic resistance $[1,2]$. The recent trend of using a large water storage tank 
calls for the development [3] of sophisticated seismic-proof design practices that strike a balance between seismic resistance and economy. The sophistication of design practices requires a detailed understanding of the vibratory behaviours of a water storage tank during an earthquake. A large cylindrical water storage tank, because of its large radius/wall-thickness ratio and the flexible property of its relatively thin sidewall, is particularly prone to fluid-structure coupling vibrations when reacting to seismic motions.

Several researchers including Veletsos et al. [4] and Fujita [5] have been studied the relationship between the seismic design for the tank and the fluidstructure coupling vibrations such as sloshing and bulging. Therefore, the current seismic designs consider sloshing and beam-type vibration, which has the axial half wave number $m \geq 1$ and the circumferential wave number $n=1$. However, the influence of oval-type vibration, which has $m \geq 1$ and $n \geq 2$, on the response of the tank remains still unknown.

This paper reports on the results of a large input vibration test which is conducted using a water storage model tank to study how beam-type vibrations are affected by oval-type vibrations and the theoretical analysis of the test results.

Large input excitation tests are performed, in which the test tank is excited by sinusoidal waves of a resonance frequency. The response of the tank, which means beam-type vibrations, does not grow in proportion to the input acceleration above a certain level. Since in the tests, oval-type vibrations occur largely on the sidewall of tank, the interaction of the oval vibrations over the beam-type vibrations is considered. Assuming the deformation of the sidewall of tank by the oval-type vibrations reduces the flexural rigidity of the tank, a nonlinear vibration model is proposed to explain the results of the large input excitation tests.

\section{Experiment}

In order to conduct large input excitation tests, a vibration test apparatus that consisted of a large hydraulic shaking table and a measuring system is used. Figure 1 shows the test tank used in the test. The cylinder portion of the tank is made of aluminium alloy. A metal flange is attached to the top and bottom of the cylinder portion. A platform is used to hold the tank on the shaking table.

Figure 2 shows the positions of various sensors and gauges attached to the test tank. Accelerometers are attached to the tank top and to the shaking table. Since the rigid flange on the tank top would inhibit oval-type vibrations, measurements taken on the tank top would refer mostly to beam-type vibrations. Oval-type vibrations are monitored using a number of strain gauges that are attached side by side to the sidewall at the height of $800 \mathrm{~mm}$ from the tank bottom, covering a part of the circumference of the tank from $-18^{\circ}$ to $+90^{\circ}$ at an interval of $6^{\circ}$. Several pressure sensors are attached to the inside of the tank wall one above the other at the $0^{\circ}$ position. 


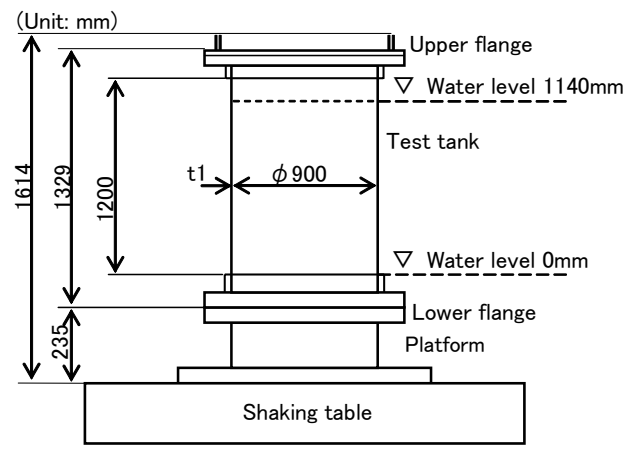

Figure 1: $\quad$ Test tank.

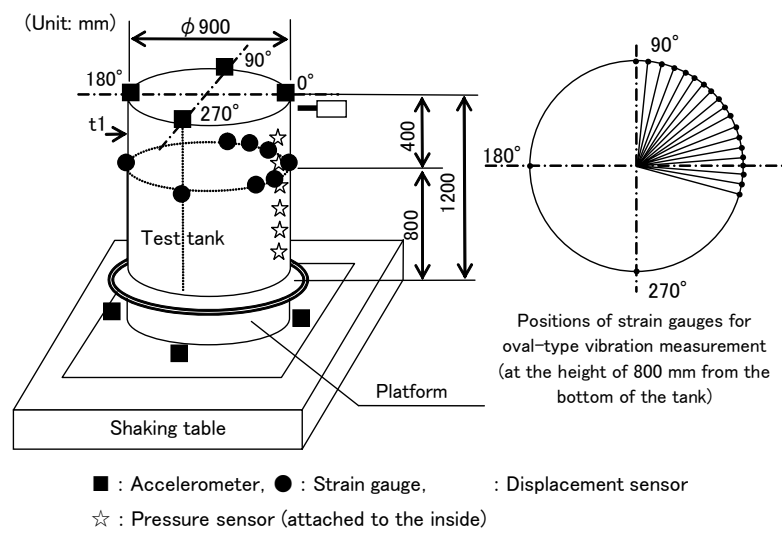

Figure 2: $\quad$ Measuring points.

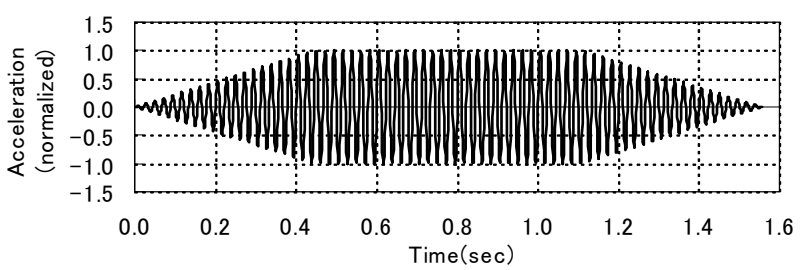

Figure 3: $\quad$ Input waveform for large input excitation test.

The test tank is filled with water to $95 \%(1140 \mathrm{~mm})$ level and then excited horizontally by sinusoidal waves between $0^{\circ}$ and $180^{\circ}$. Large input excitation tests are conducted with the input waveform of sinusoidal excitations as shown in Figure 3. The excitation frequency is $40 \mathrm{~Hz}$, which is the resonance frequency of the test tank. The test is conducted for two input acceleration levels, which are $1.0 \mathrm{G}$ and $2.0 \mathrm{G}$. 


\section{Results}

\subsection{Large input excitation test}

Figure 4, which is for the input accelerations of $1.0 \mathrm{G}$ and $2.0 \mathrm{G}$, shows the timehistory waveforms of the input acceleration and of the response acceleration measured at the tank top.

In spite of the fact that the input acceleration is doubled (see Figure 4(b)), the maximum amplitude of the response acceleration remains at the same level as in the test case of Figure 4(a). This indicates that the response of the tank, which means beam-type vibration, reduces. Furthermore, as apparent in Figure 4, the response acceleration waveforms begin to show a complex pattern from a certain point during the vibration test, giving an impression that the test tank is not vibrating at a uniform frequency.

This phenomenon suggests that the vibration characteristics of the beam-type vibration changes during large input excitation.
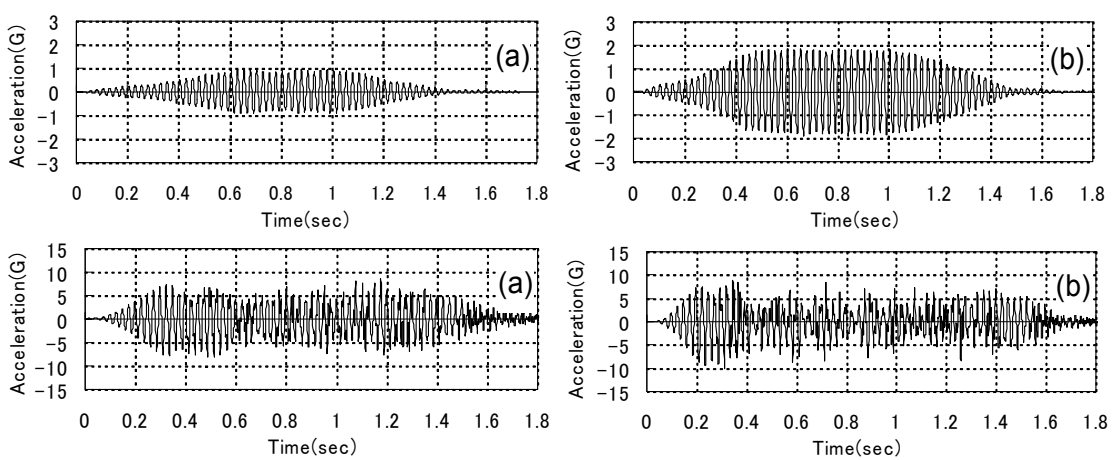

Figure 4: Time-history waveforms of input acceleration (upper chart) and response acceleration (lower chart) during large input excitation tests of (a) $1.0 \mathrm{G}$ and (b) $2.0 \mathrm{G}$.

\subsection{Oval-type vibration}

Figure 5 shows the examples of circumferential distribution of circumferential strains that appear on the sidewall of the test tank for large input excitation. They are plotted at the early stage and the middle stage during excitation. A petal-like distribution pattern indicates the presence of oval-type vibrations. The magnitude of the strain represents the amplitude of oval-type vibration. In comparison of two examples, it is apparent that the oval-type vibration appears largely at the middle stage during excitation. Considering the results of Figure 4, the response of the tank is found to reduce at the time when the oval-type vibration appears largely. Therefore, it is concluded that the beam-type vibration and the oval-type vibration interact closely. 

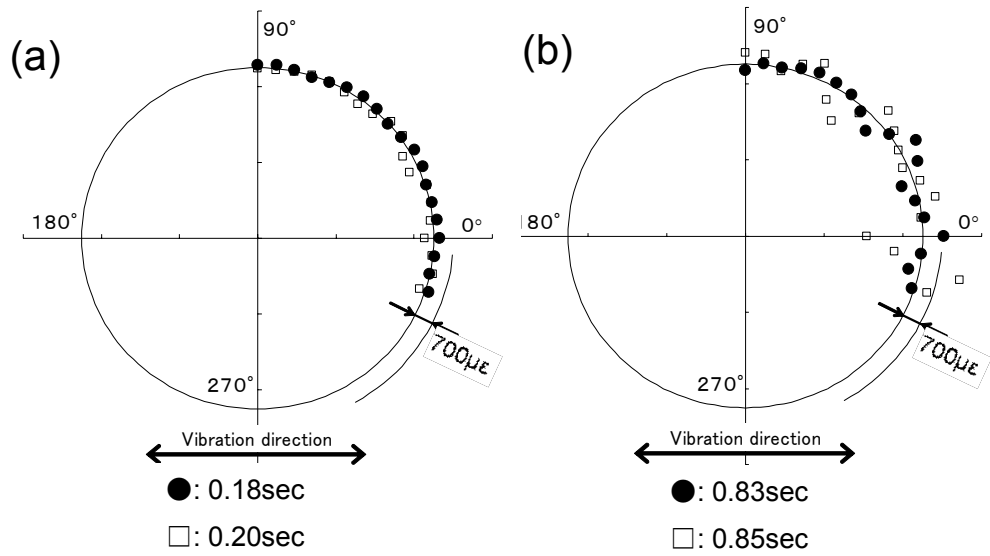

Figure 5: Examples of circumferential distribution of circumferential strain in (a) early stage and (b) middle stage during large input excitation test of $2.0 \mathrm{G}$.

\section{Discussion}

\subsection{Coupling between beam-type vibration and oval-type vibration}

Let us discuss the coupling between beam-type vibrations and oval-type vibrations. Figure 6 shows the conceptual diagram illustrating the tank is oscillated with the coupling between beam-type vibration and oval-type vibration. This figure indicates that the sidewall of tank is deformed largely by the oval-type vibration amplitude. Thus, it is supposed that the flexural rigidity of the tank reduces at this time.

Let us verify this hypothesis by the static analysis using the finite element method (FEM). As shown in Figure 7, the FEM analysis model of the tank is given the mode shape of the oval-type vibration as an imperfection shape, and then the flexural rigidity of the tank model is calculated using FEM. In the calculation, the amount of the imperfection means the amplitude of oval-type vibration. That is, the flexural rigidity of the tank is calculated parametrically for various magnitude of the oval-type vibration amplitude. Figure 8 shows the results of the calculation for the oval-type vibration with the axial half wave number $m=3$ and the circumferential wave number $n=14$. In the figure, the horizontal axis is the amplitude of oval-type vibration and the vertical axis is the ratio of the flexural rigidity with oval-type vibrations for the one without ovaltype vibrations. Figure 8 indicates that the flexural rigidity is smaller as the ovaltype vibration amplitude is larger. In other words, the resonance frequency of beam-type vibrations is lowered by coupling with oval-type vibrations. 
126 Fluid Structure Interaction and Moving Boundary Problems IV

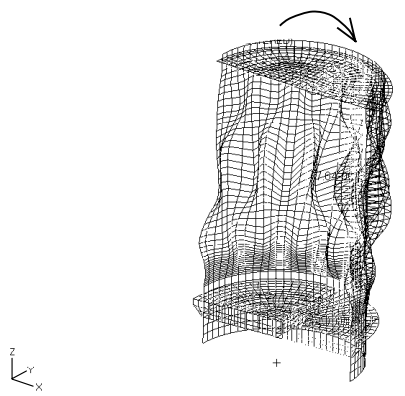

Figure 6: Conceptual diagram of vibration behaviour of a cylindrical tank when beam-type $(m=1, n=1)$ and oval-type $(m=3, n=14)$ vibrations are coupled.

\section{Out-of-plane deformation caused by displacement-amplitude}

of oval-type vibration given as an initial imperfection

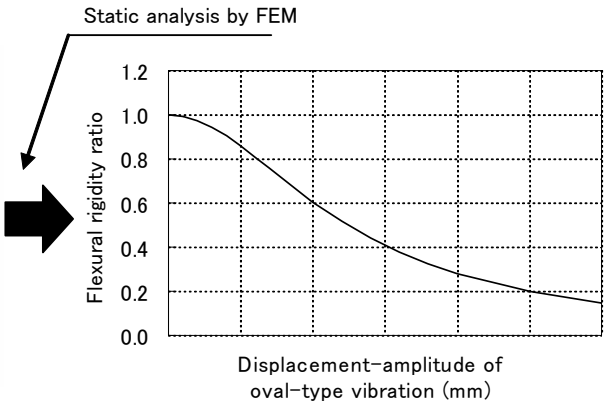

FEM static analysis model oval-type vibration $(\mathrm{mm})$

Figure 7: Procedure of flexural rigidity analysis of a cylindrical tank; the arrow means maximum deformation due to the amplitude of the oval-type vibration.

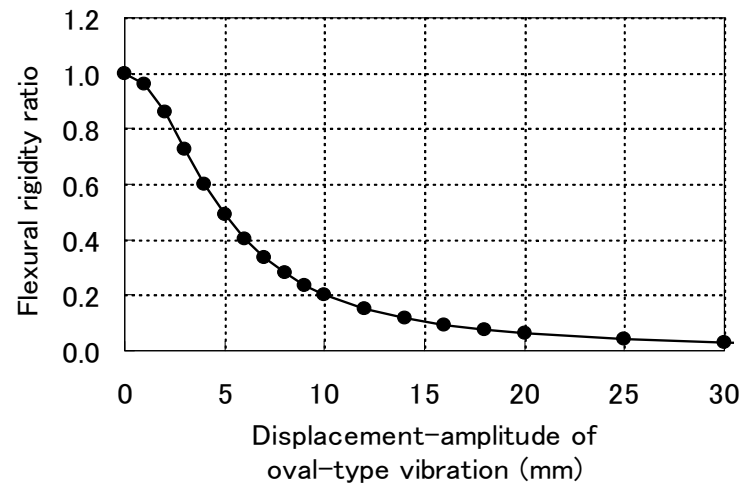

Figure 8: Relationship between flexural rigidity of a cylindrical tank and amplitude of oval-type vibration $(m=3, n=14)$. 


\subsection{Nonlinear single-degree-of-freedom system model}

From the results of the above discussion, an equivalent nonlinear single-degreeof-freedom system model (SDOF model) is proposed to express the vibration behaviour of the tank with coupling between beam-type vibrations and oval-type vibrations as a simplified model. The spring constant of the proposed model expresses the flexural rigidity of the tank. The spring constant changes by the magnitude of the oval-type vibration amplitude.

Here, let us consider an equation of motion that expresses the model. Assuming that the tank is a beam model with a single-degree-of-freedom, an equation of motion for this model is as follows:

$$
m_{0} \ddot{x}+c \dot{x}+k_{N L} x=-m_{0} \alpha
$$

where $m_{0}$ is the mass, $x$ the amount of displacement, $c$ the damping coefficient, $k_{N L}$ the nonlinear spring constant depended on the amplitude of ova-type vibration, and $\alpha$ the acceleration by external force like earthquake motion. When the natural frequency of the beam-type vibration without the oval-type vibration is $f_{L}, k_{N L}$ of eqn (1) corresponds to a linear spring constant, which expresses $k_{L}$.

$$
\begin{aligned}
f_{L} & =\frac{1}{2 \pi} \sqrt{\frac{k_{L}}{m_{0}}} \\
k_{L} & =\left(2 \pi f_{L}\right)^{2} m_{0}
\end{aligned}
$$

The damping coefficient $c$ is expressed as follows:

$$
c=2 \cdot \varsigma \cdot m_{0} \cdot 2 \pi f_{L}=4 \pi \varsigma \cdot m_{0} \cdot f_{L}
$$

where $\varsigma$ is the damping ratio.

When the oval-type vibration appears, $k_{N L}$ is a nonlinear. This expresses the following relationship:

$$
\frac{k_{N L}}{k_{L}}=r(z)
$$

where $r(z)$ means a nonlinearity depending on the magnitude of the oval-type vibration amplitude $z$. In other words, it is a changing rate of the flexural rigidity by the oval-type vibration amplitude.

Using eqns (2) to (5), eqn (1) is as follows:

$$
\ddot{x}+4 \pi \varsigma \cdot f_{L} \dot{x}+\left(2 \pi f_{L}\right)^{2} \cdot r(z) \cdot x=-\alpha
$$

In the numerical simulation stated later, the relationship between the flexural rigidity ratio and the oval-type vibration amplitude, which is obtained by FEM static analysis in 4.1 , is substituted for the changing rate of the flexural rigidity $r(z)$. 


\subsection{Numerical simulation}

The response of the tank is simulated by assigning the parameter values listed in Table 1 to this analysis model. The natural frequency for the primary beam-type vibrations and the natural frequency for oval-type vibrations are calculated by the FEM analysis. In earlier vibration tests by Maekawa et al [6], oval-type vibrations are most prominent at double the excitation frequency. The simulation using the proposed model assumes the appearance of oval-type vibrations at double the natural frequency for the primary beam-type vibrations. The other values of parameters using in numerical simulation such as damping ratio are decided based on the earlier studies [6].

Table 1: Vibration parameters for response analysis using the SDOF model.

\begin{tabular}{|c|c|c|}
\hline & Item & Value \\
\hline \multirow[t]{2}{*}{$\begin{array}{l}\text { Beam-type } \\
\text { vibration }\end{array}$} & $\begin{array}{l}\text { Natural frequency for primary } \\
\text { beam-type vibration }\end{array}$ & $45.0 \mathrm{~Hz}$ \\
\hline & Damping ratio & $2 \%$ \\
\hline \multirow[t]{4}{*}{$\begin{array}{l}\text { Oval-type } \\
\text { vibration }\end{array}$} & $\begin{array}{l}\text { Natural frequency for oval-type } \\
\text { vibration }\end{array}$ & $95.7 \mathrm{~Hz}$ \\
\hline & $\begin{array}{l}\text { Axial half wave number }(m) \text { for } \\
\text { oval-type vibration }\end{array}$ & 3 \\
\hline & $\begin{array}{l}\text { Circumferential wave number } \\
(n) \text { for oval-type vibration }\end{array}$ & 14 \\
\hline & $\begin{array}{l}\text { Time of appearance of oval-type } \\
\text { vibration }\end{array}$ & $0.235 \mathrm{~s}$ \\
\hline Input vibration & \multicolumn{2}{|c|}{ Sinusoidal wave } \\
\hline
\end{tabular}

The relationship between the flexural rigidity ratio of the tank and the amplitude of oval-type vibrations is determined using an FEM analysis as shown in Figure 8 . The flexural rigidity ratio is assumed to go and back from the maximum value $(r(z)=1)$ to the minimum value over and over in the frequency of the oval-type vibration. Under such repetition, an input waveform is given to the proposed model, and then the numerical analysis is conducted.

Figure 9 shows the results of the numerical simulation by the proposed model, which is the case of the input acceleration of $2.0 \mathrm{G}$. This figure presents a time-history waveform that closely resembles that shown in Figure 4. This result shows the proposed model can simulate the response behaviour of the tank. This model represents the flexural rigidity of tank or the resonance frequency of beam-type vibration depends on the amplitude of oval-type vibration. Therefore, it is concluded from this result that a drop of the resonance frequency of the beam-type vibration due to the coupling with oval-type vibrations must restrict the response of the tank. 

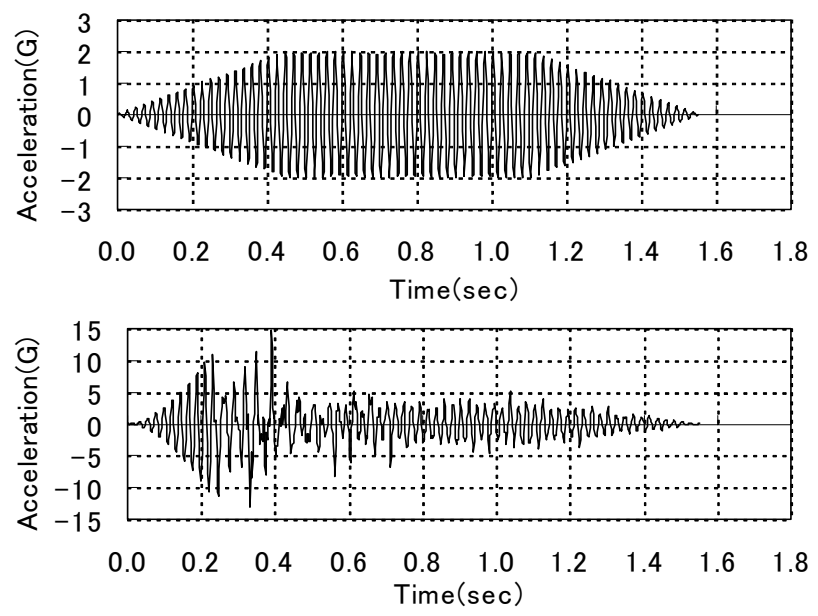

Figure 9: Time-history waveforms of input acceleration (upper chart) and response acceleration (lower chart) by numerical simulation using the proposed nonlinear SDOF model.

\section{Conclusions}

It is found that the vibration response of a cylindrical water storage tank, which means beam-type, reduces in the large input excitation. The response reduction of the tank can be reasonably explained by decrease of the flexural rigidity of the tank caused by the coupling between beam-type vibrations and oval-type vibrations. The proposed nonlinear SDOF model simulates the vibratory characteristics of the tank caused by the coupling effect very well. Therefore, it is demonstrated both empirically and analytically that the response of beam-type vibrations is reduced and the resonance frequency of beam-type vibrations is lowered by coupling with oval-type vibrations.

\section{References}

[1] JEA (Japan Electric Association), JEAG 4601-1987: Technical Guidelines for Aseismic Design of Nuclear Power Plants, JEA, 1987, (in Japanese).

[2] European Committee for Standardization, Eurocode 8: Design Provisions of Earthquake Resistance of Structures, Part 4: Silos, Tanks and Pipelines, 1998.

[3] Shibata, H., Suzuki, K. \& Ikeda, M., Development of seismic design code for high pressure gas facilities in Japan. Journal of Pressure Vessel Technology, 126, pp. 2-8, 2004.

[4] Veletsos, A. S., ASCE, M. \& Yang, J.Y., Earthquake response of liquidstorage tanks. Proc. of the $2^{\text {nd }}$ Engineering Mechanics Specialty Conf., pp.124, 1977. 
130 Fluid Structure Interaction and Moving Boundary Problems IV

[5] Fujita, K, A seismic response analysis of a cylindrical liquid storage tank including the effect of sloshing. Bulletin of the JSME, 24(195), pp.16341641, 1981.

[6] Maekawa, A., Shimizu, Y., Suzuki, M. \& Fujita, K., Experimental study of coupling vibration characteristics between a thin cylindrical water storage tank and its contained liquid. Proc. 2005 ASME Pressure Vessels and Piping Division Conf., PVP2005-71256, pp.1-8, 2005. 